\title{
16. MAGNETIC PROPERTIES OF BASALTS FROM THE CENTRAL NORTH ATLANTIC OCEAN ${ }^{1}$
}

\author{
Guy M. Smith and Subir K. Banerjee, Department of Geology and Geophysics, University of Minnesota ${ }^{2}$
}

\begin{abstract}
The magnetic properties of 56 samples of basalt from DSDP Leg 82 were studied in order to examine regional variations as well as the general question of the origin or remanence. Magnetization was carried, for the most part, by typical low temperature oxidized titanomagnetites, although two samples did show anomalous thermomagnetic curves. The natural remanence is distinctly different from an anhysteretic remanent magnetization and is hypothesized (by inference) to also be different from a thermoremanent magnetization (TRM) also. This suggests that alteration not only reduces the initial TRM but also changes it to chemical remanent magnetization with a significantly different magnetic character. An examination of thermomagnetic data tentatively suggests that the ulvospinel content of the titanomagnetites may be more variable than is commonly assumed. With the exception of a slight increase in saturation magnetization with decreasing latitude, no significant regional variations were evident.
\end{abstract}

\section{INTRODUCTION}

This paper reports on the magnetic properties of 56 samples of basalt from eight of the nine sites drilled on DSDP Leg 82 (no significant amount of basalt was recovered from Site 560). These sites were distributed over a fairly broad area and thus offer an opportunity to study the extent to which magnetic properties of the upper basement vary horizontally.

We measured a number of magnetic parameters including:

1. intensity, direction, and stability of natural remanent magnetization (NRM);

2. weak field susceptibility $\left(\chi_{0}\right)$.

3 . hysteresis loop parameters, i.e., saturation magnetization, $\mathrm{J}_{s}$; saturation remanence, $\mathrm{J}_{\mathrm{rs}}$; coercivity, $\mathrm{H}_{\mathrm{c}}$; remanent coercivity, $\mathrm{H}_{\mathrm{cr}}$; and paramagnetic susceptibility, $\chi_{\mathrm{p}}$.

4. Curie temperature, $T_{c}$, and thermomagnetic curve analysis; and

5. intensity and stability of anhysteretic remanent magnetization (ARM).

\section{METHODS}

Magnetic remanence measurements were made on a Schonstedt spinner magnetometer. Alternating field (AF) demagnetization was performed on a single axis Schonstedt demagnetizer. Each step was repeated for three orthogonal directions to ensure complete demagnetization. For ARM induction, we also used this instrument with a $0.5 \mathrm{Oe}$ static bias field and a peak AF field (coaxial) of $1000 \mathrm{Oe}$.

Hysteresis loops were obtained with a Princeton Applied Research vibrating sample magnetometer coupled to an $\mathrm{x}-\mathrm{y}$ recorder. Thermomagnetic measurements were also made on this instrument with an automatically controlled heating rate $\left(20^{\circ} \mathrm{C} /\right.$ minute $)$ in a vacuum of better than $10^{-6}$ torr. Temperature calibration is based on measurements of pure $\mathrm{Ni}\left(\mathrm{T}_{\mathrm{c}}=358^{\circ} \mathrm{C}\right)$ and pure $\mathrm{Fe}_{3} \mathrm{O}_{4}\left(\mathrm{~T}_{\mathrm{c}}=580^{\circ} \mathrm{C}\right)$. Values are obtained with the graphical method (Moskowitz, 1981).

1 Bougault, H., Cande, S. C., et al., Init. Repts. DSDP, 82: Washington (U.S. Govt. Printing Office).

2 Address: Department of Geology and Geophysics, University of Minnesota, Minneapolis, Minnesota 55455 .
Weak field susceptibility was measured with a Conservation Instruments ("Bartington") bridge.

\section{RESULTS}

\section{Natural Remanent Magnetization}

NRM intensities vary from $7.74 \times 10^{-3}$ to $1.77 \times$ $10^{-4} \mathrm{emu} \cdot \mathrm{cm}^{-3}$. Average values for each site and rock type are given in Table 1 (details are in Appendix A at the end of this chapter). With the exceptions of Sites 557 and 559, the site-averaged values are fairly close. Site 557 is slightly high but this is based on only two samples, which may not be representative. Site 559 is quite low but, again, the data represent only four samples and may be misleading. The first six sites have higher NRM intensities for pillow interiors than margins but the reverse is true for Sites 563 and 564. Flow interiors are also more strongly magnetized than margins with the exception of Site 562. Although these may be trends in these data, their validity seems questionable and no attempt to discover possible trends will be made here.

Median demagnetizing fields $\left(\mathrm{MDF}_{\mathrm{N}}\right)$ run quite high generally with many in excess of 400 Oe and several above 1000 Oe. The notable exception is Site 559 with MDF's of 99 and 113 Oe. Hole 558 flow and pillow margins tend to have a somewhat higher MDF than their respective interiors, but otherwise no pattern is apparent.

Samples frequently have a small $(<10 \%)$ low coercivity component $(<100 \mathrm{Oe})$, which is generally steep and positive. Much of this is probably the result of relatively recent viscous remanence. Some have nearly vertical inclinations, but this may be an artifact of drilling. As these components are generally small and easily demagnetized, they represent no significant problem.

A few samples show multicomponent behavior persisting to such large fields that a stable secondary remanence is probable (see Appendix A). The difference in inclination is large enough so that magnetization must have been acquired in two or more episodes separated by tectonic rotation and/or a sufficient time lapse for 
Table 1. Natural remanent magnetization (NRM) values (in $\mathrm{emu} / \mathrm{cm}^{3}$ ).

\begin{tabular}{|c|c|c|c|c|c|}
\hline \multirow[b]{2}{*}{ Hole } & \multicolumn{2}{|c|}{ Pillows } & \multicolumn{2}{|c|}{ Flows } & \multirow[b]{2}{*}{ Average } \\
\hline & Margin & Interior & Margin & Interior & \\
\hline 556 & $1.27 \times 10^{-3}$ & $3.53 \times 10^{-3}$ & $2.20 \times 10^{-3}$ & $3.94 \times 10^{-3}$ & $3.04 \times 10^{-3}$ \\
\hline 557 & & & & & $\begin{array}{l}7.59 \times 10^{-} \\
2.20 \times 10^{-}\end{array}$ \\
\hline 558 & $8.84 \times 10^{-4}$ & $2.66 \times 10^{-3}$ & $8.88 \times 10^{-4}$ & $5.30 \times 10^{-3}$ & $2.20 \times 10$ \\
\hline 559 & $4.32 \times 10^{-4}$ & $5.87 \times 10^{-4}$ & & & $5.10 \times 10^{-}$ \\
\hline 561 & $2.35 \times 10^{-3}$ & $3.31 \times 10^{-3}$ & & $2.22 \times 10^{-3}$ & $2.53 \times 10^{-}$ \\
\hline 562 & $1.32 \times 10^{-3}$ & $2.34 \times 10^{-3}$ & $2.00 \times 10^{-3}$ & $1.40 \times 10^{-3}$ & $1.85 \times 10^{-}$ \\
\hline 563 & $4.96 \times 10^{-3}$ & $1.95 \times 10^{-3}$ & & & $3.46 \times 10^{-}$ \\
\hline 564 & $4.46 \times 10^{-3}$ & $2.12 \times 10^{-3}$ & $1.68 \times 10^{-3}$ & $2.91 \times 10^{-3}$ & $2.78 \times 10^{-}$ \\
\hline Average & $2.79 \times 10^{-3}$ & $2.36 \times 10^{-3}$ & $1.65 \times 10^{-3}$ & $3.15 \times 10^{-3}$ & $3.00 \times 10^{-}$ \\
\hline
\end{tabular}

Note: Samples that could not be assigned to a particular rock type were included in the final averages.

the field to change significantly (1000 yr. or so). This phenomenon seems a local one; nearby samples with otherwise similar characteristics show no such behavior. Multicomponent remanence does not seem to be associated with any particular rock type.

Koenigsberger ratios were generally large, usually in excess of 10 and often much higher.

\section{Hystersis Loop Parameters}

Hysteresis loop parameters provide a measure of the intrinsic magnetic properties of the samples and are useful in studying the origin of remanence. They are given in Appendix B at the end of this chapter.

Saturation magnetization, $\mathbf{J}_{s}$, is a measure of the total amount of magnetic material present (if the composition is known, it is an exact measure). Average values of $\mathrm{J}_{\mathrm{s}}$ are given in Table 2. With the exception of Sites 562 and 563 , the variation of $\mathrm{J}_{\mathrm{s}}$ between rock types is similar to that of $J_{N}$ and suggests that the primary cause of variation in remanence is simply the amount of magnetic carrier present. There appears to be an increase in $\mathbf{J}_{\mathrm{s}}$ as the latitude decreases, although the small number of sites precludes any meaningful statistical test.

Coercivity, $\mathrm{H}_{\mathrm{c}}$, is similar, though not identical, to the $\mathrm{MDF}$ as a measure of magnetic stability. Figure 1A shows a comparison of $\mathrm{H}_{\mathrm{c}}$ and $\mathrm{MDF}_{\mathrm{N}}$ and Figure 1B shows $\mathrm{H}_{\mathrm{c}}$ and $\mathrm{MDF}_{\mathrm{A}}$. As can be seen, there is substantially less scatter for $\mathrm{H}_{\mathrm{c}}-\mathrm{MDF}_{\mathrm{A}}$ graph. This is one piece of evidence (to be discussed later) that ARM and NRM are significantly different in these samples.
The two ratios, $\mathrm{J}_{\mathrm{rs}} / \mathrm{J}_{\mathrm{s}}$ and $\mathrm{H}_{\mathrm{cr}} / \mathrm{H}_{\mathrm{c}}$, are commonly interpreted as indicators of domain state (Day et al., 1977). The values for these samples suggest that they contain predominantly single-domain or small pseudo-single domain grains with sizes of a few microns at most. An alternate possibility is that the sample contains larger (10$20 \mu \mathrm{m}$ ) grains that are in a metastable single-domain state (Halgedahl and Fuller, 1983). Future polished section work should help clarify this issue.

\section{Curie Temperature}

The Curie temperature, $T_{c}$, is the temperature below which a magnetic material becomes magnetically ordered. The value for titanomagnetites is very sensitive to both Ti content (usually expressed as the proportion of ulvospinel to magnetite) and degree of low temperature oxidation (Syono, 1965; Readman and O'Reilly, 1972; Moskowitz and Banerjee, 1981). Generally, $T_{c}$ decreases with increasing $\mathrm{Ti}$ content and increases with oxidation. When a low temperature oxidized titanomagnetite (titanomaghemite) is heated, it produces the characteristic thermomagnetic curve seen in Figure 2A. The second maximum is due to the fact that titanomaghemite is metastable and inverts upon heating to a two-phase mixture with compositions close to magnetite and ilmenite. This causes a large difference in $\mathrm{T}_{\mathrm{c}}$ measured from the heating and cooling curves, as well as a marked increase in magnetization.

There were only a few exceptions to the above pattern. Two samples had an initial $T_{c}$ greater than $450^{\circ} \mathrm{C}$

Table 2. Saturation magnetization $\left(\mathrm{J}_{\mathrm{S}}\right)$ values (in $\mathrm{emu} \cdot \mathrm{g}^{-1}$ ).

\begin{tabular}{ccccccc}
\hline & \multicolumn{2}{c}{ Pillows } & & \multicolumn{2}{c}{ Flows } & \\
\cline { 2 - 3 } Hole & Margin & Interior & & Margin & Interior & Average \\
\hline 556 & $5.86 \times 10^{-2}$ & $1.19 \times 10^{-1}$ & & $6.13 \times 10^{-2}$ & $1.05 \times 10^{-1}$ & $8.78 \times 10^{-2}$ \\
557 & & & & & & $1.48 \times 10^{-1}$ \\
558 & $8.43 \times 10^{-2}$ & $1.48 \times 10^{-1}$ & & $7.82 \times 10^{-2}$ & $1.44 \times 10^{-1}$ & $1.11 \times 10^{-1}$ \\
559 & $7.18 \times 10^{-2}$ & $9.66 \times 10^{-2}$ & & & & $8.41 \times 10^{-2}$ \\
561 & $2.80 \times 10^{-1}$ & $3.16 \times 10^{-1}$ & & & $3.00 \times 10^{-1}$ & $2.99 \times 10^{-1}$ \\
562 & $2.57 \times 10^{-1}$ & $1.67 \times 10^{-1}$ & & $3.83 \times 10^{-1}$ & $2.77 \times 10^{-1}$ & $2.45 \times 10^{-1}$ \\
563 & $2.66 \times 10^{-1}$ & $3.24 \times 10^{-1}$ & & & & $2.95 \times 10^{-1}$ \\
564 & $3.17 \times 10^{-1}$ & $2.00 \times 10^{-1}$ & & $1.05 \times 10^{-1}$ & $3.72 \times 10^{-1}$ & $2.56 \times 10^{-1}$ \\
Average & $1.91 \times 10^{-1}$ & $1.96 \times 10^{-1}$ & & $1.57 \times 10^{-1}$ & $2.40 \times 10^{-1}$ & $1.99 \times 10^{-1}$ \\
\hline
\end{tabular}

Note: Samples that could not be assigned to a particular rock type were included in the final averages. 

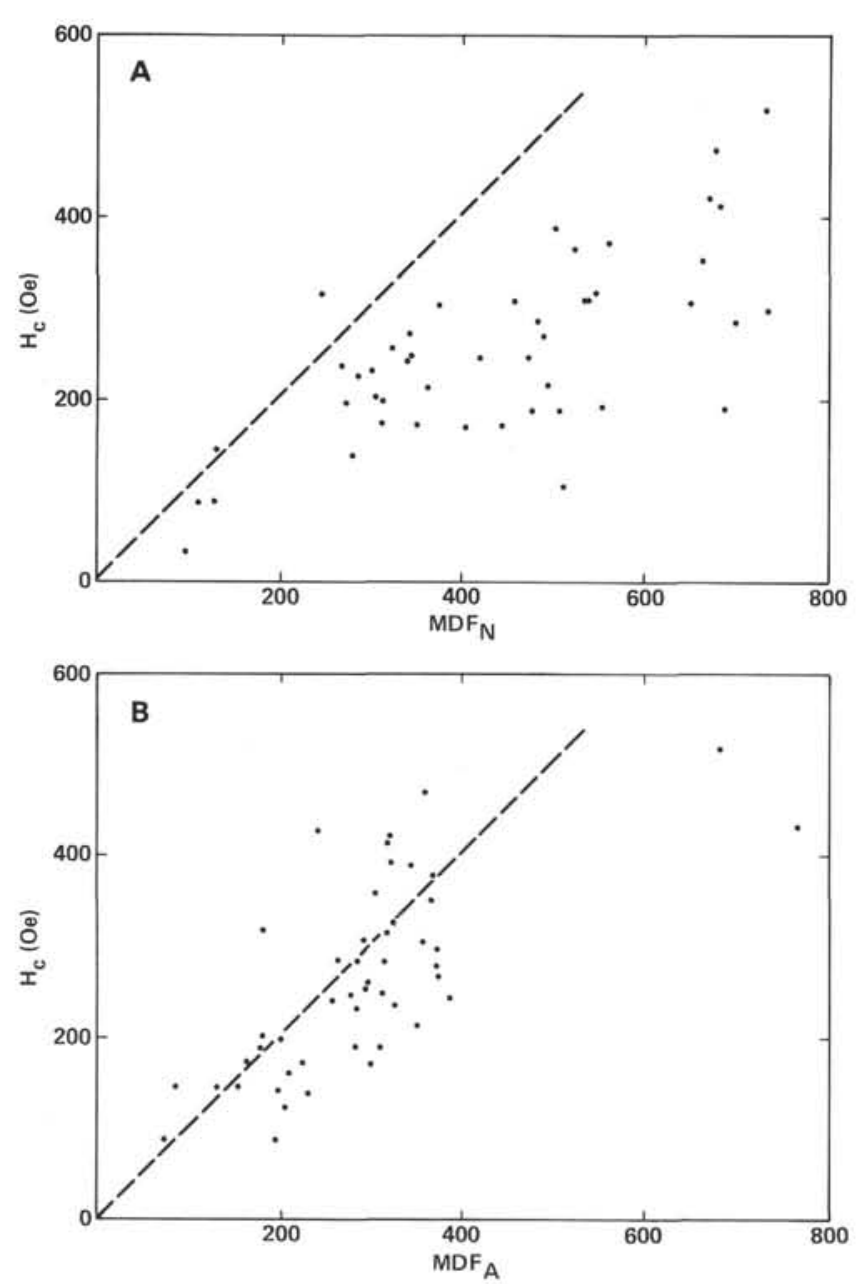

Figure 1. A. Coercivity $\left(\mathrm{H}_{\mathrm{c}}\right)$ versus mean demagnetizing field for natural remanent magnetization $\left(\mathrm{MDF}_{\mathrm{N}}\right)$. B. Coercivity $\left(\mathrm{H}_{\mathrm{c}}\right)$ versus mean demagnetizing field for anhysteretic remanent magnetization $\left(\mathrm{MDF}_{\mathrm{A}}\right)$.

(556-8-2, 80-83 $\mathrm{cm}$ and 564-6-2, 104-107 cm). Both were pillow margins and may have been partially deuterically altered at high temperature. Two other samples (561-3-1, $67-70 \mathrm{~cm}$ and $562-5-2,104-107 \mathrm{~cm}$ ) have somewhat unusual curves (Fig. 2B) with normal heating portions but apparently very low $T_{c}$ cooling curves. We have, as yet, no explanation for this odd behavior, although reduction caused by presence of sulfides is a possibility. Two samples $(557-1-1,46-49 \mathrm{~cm}$ and $562-1-2,27-30 \mathrm{~cm})$ had very low $\mathrm{T}_{\mathrm{c}}$ values and appear to be relatively unaltered.

Averages for the remaining more or less normal samples are given in Table 3. Pillow margins have consistently higher $T_{c}$ suggesting that they are more altered than their interiors. The same is true for flows, with the exception of Site 562 . There seems to be a general trend towards higher $T_{c}$ 's for older rocks but it is not very well defined.

It has been commonly accepted that the ulvospinel content of marine titanomagnetites is relatively constant (Johnson, 1979), although Steiner (1982) suggests that more variability may exist. Unfortunately, this is a difficult question to approach experimentally because the
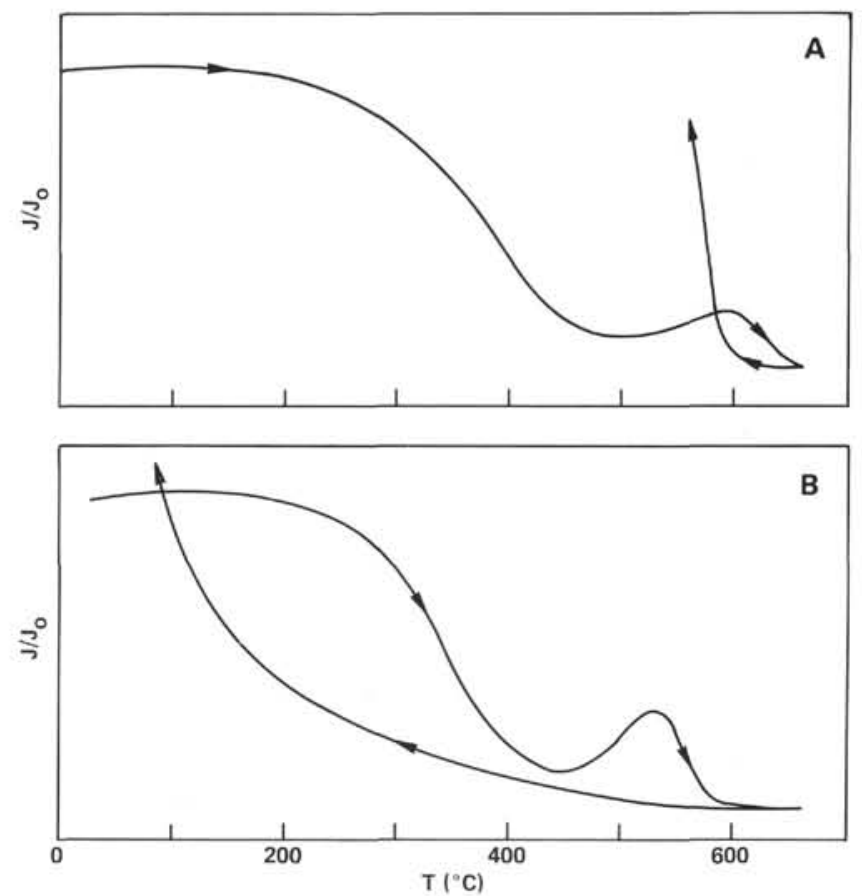

Figure 2. A. Thermomagnetic curve for a typical low temperature oxidized basalt (Sample 556-8-2, 6-9 cm). B. Atypical thermomagnetic curve (Sample 571-3-1, 67-70 cm) shown by two samples. Vertical axis is the relative magnetization $\left(\mathrm{J} / \mathrm{J}_{\mathrm{o}}\right)$ in arbitrary units. Horizontal axis (temperature) is uncorrected for instrumental offset (actual values are somewhat lower).

Table 3. Initial Curie temperatures $\left(\mathrm{T}_{\mathrm{c}}\right)$ in ${ }^{\circ} \mathrm{C}$.

\begin{tabular}{ccccccc}
\hline & \multicolumn{2}{c}{ Pillows } & & \multicolumn{2}{c}{ Flows } & \\
\cline { 2 - 3 } Hole & Margin & Interior & & Margin & Interior & Average \\
\hline 556 & 405 & 325 & & 365 & 340 & 357 \\
557 & & & & & 273 \\
558 & 353 & 297 & & 328 & 313 & 325 \\
559 & 355 & 338 & & & 346 \\
561 & 375 & 335 & & & 323 & 339 \\
562 & 260 & 275 & & 265 & 338 & 284 \\
563 & 414 & & & & & \\
564 & 423 & 335 & & 365 & 285 & 315 \\
Average & 369 & 318 & & 331 & 320 & 333 \\
\hline
\end{tabular}

Note: Samples that could not be assigned to a particular rock type were included in the final averages.

grains that carry much of the remanence are too small for direct measurement of their composition (e.g., by electron microprobe). Curie points are governed by both composition and oxidation state and hence are ambiguous. One way to circumvent this problem is suggested by O'Reilly (1983) who shows that for his synthetic $\mathrm{x}=0.6$ titanomaghemites, there is a definite relationship between oxidation state (or $T_{c}$ ) and the ratio of $J_{s}$ before inversion to that after inversion $\left(\mathrm{J}_{\mathrm{f}} / \mathrm{J}_{\mathrm{i}}\right)$. All of our samples were heated well beyond the inversion temperature $\left(\sim 350^{\circ} \mathrm{C}\right.$, O'Reilly, 1983) in the process of measuring $\mathrm{T}_{c}$ (maximum temperature was about $620^{\circ} \mathrm{C}$ ). Although the heating runs were relatively rapid $\left(20^{\circ} \mathrm{C} / \mathrm{min}\right)$, reruns of several samples showed little or no additional change in $\mathrm{J}_{s}$, indicating that the bulk of the inversion process was com- 
plete after the first heating. Figure 3 shows our data along with the trend from O'Reilly (1983). Two things are immediately obvious; (1) there is no trend and (2) most of our values exceed those of O'Reilly, some by a substantial amount.

It is possible that there are some differences in the way in which the samples were inverted but this seems unlikely. Maximum temperatures were close to those of O'Reilly, and variations in vacuum and the possible presence of reducing agents do not seem sufficient to produce large discrepancies, although this matter needs further study. One factor that may contribute to the scatter of the data is variability in oxidation state among the various titanomaghemite grains in a sample; $T_{c}$ tends to reflect the most oxidized grains, whereas $\mathrm{J}_{\mathrm{f}} / \mathrm{J}_{\mathrm{i}}$ includes the whole assemblage. This mechanism does not, however, explain the large values of $J_{\mathrm{f}} / \mathrm{J}_{\mathrm{i}}$ relative to O'Reilly's results. We can find two possible explanations (not mutually exclusive) that could account for this discrepancy. One is that the seafloor oxidation process differed significantly from that to which O'Reilly's samples were exposed. The other is that the compositions of oceanic titanomagnetites are not as constant as has been commonly assumed. In all probability, two, or even all three, of these possible factors are present along with others that are less obvious. Further work is clearly necessary to resolve this issue.

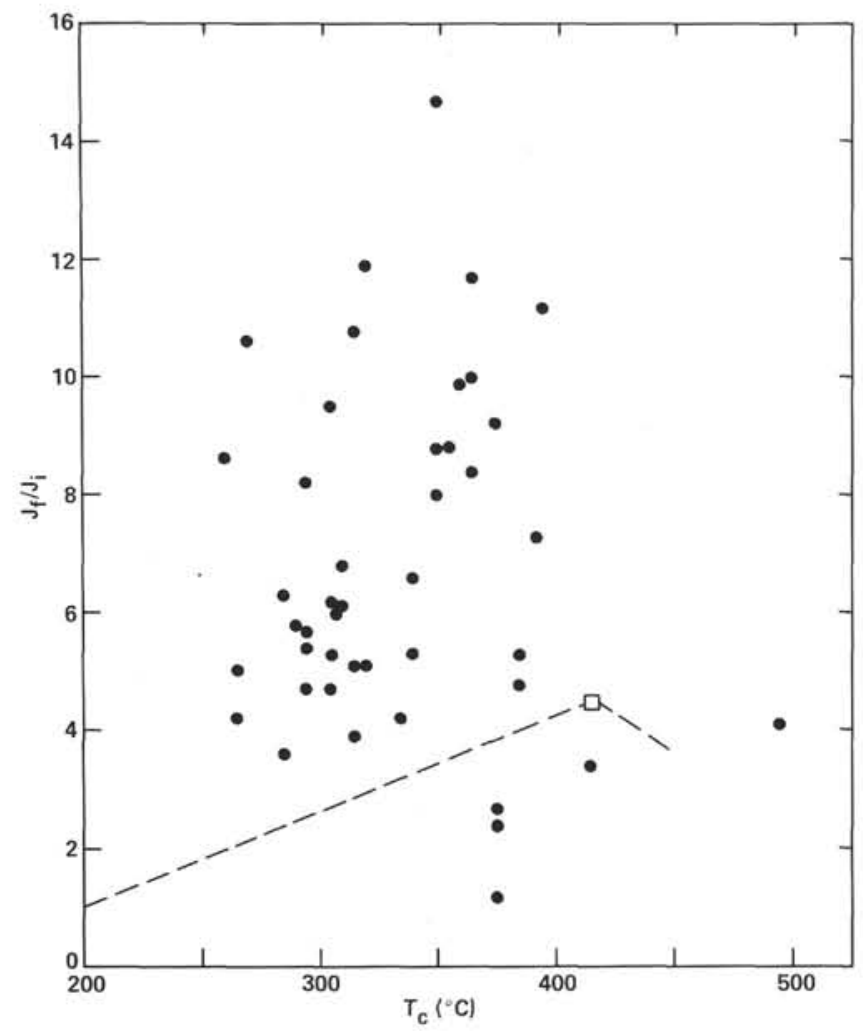

Figure 3. $\mathrm{J}_{\mathrm{f}} / \mathrm{J}_{\mathrm{i}}$ versus initial Curie temperature $\left(\mathrm{T}_{\mathrm{c}}\right)$. Samples that showed no sign of inversion were not included. $\mathrm{J}_{\mathrm{f}}$ is saturation magnetization after inversion; $\mathrm{J}_{\mathrm{i}}$ is saturation magnetization before inversion. The dashed line shows the trend of data from O'Reilly (1983).

\section{Anhysteretic Remanent Magnetization}

ARM is often used as a model for thermoremanent magnetization (TRM) because it does not require heating and consequent alteration of the sample. Levi and Merrill (1976) found that ARM intensity is usually less than TRM by a factor that varies but is generally greater than two (the exceptions were two large single crystals of magnetite that are not comparable to these samples). They also found that ARM and TRM had very similar AF demagnetization curves. In order to study the effect of low temperature oxidation on the original TRM, all samples were given an ARM, which was subsequently AF demagnetized. If the remanence is still essentially the original TRM, one would expect that the ARM intensity $\left(\mathrm{J}_{\mathrm{A}}\right)$ would be less than half of the NRM value $\left(\mathrm{J}_{\mathrm{N}}\right)$, and the median demagnetizing fields $\left(\mathrm{MDF}_{\mathrm{A}}\right.$ and $\mathrm{MDF}_{\mathrm{N}}$, respectively) should be about equal. This is generally not the case with our samples. $J_{A} / J_{N}$ is greater than 0.5 in most cases, sometimes much greater (e.g., 559-6-2, 50-53 cm), and $\mathrm{MDF}_{\mathrm{A}} / \mathrm{MDF}_{\mathrm{N}}$ generally is significantly less than 1.0 (Appendix A).

There are several sources of uncertainty in this comparison that should be considered in interpreting these data. $\mathrm{J}_{\mathrm{A}}$ is a function of the inducing field and hence may be different from the actual field in which magnetization took place. However, it should be within, at most, $\pm 50 \%$. The MDF is not very sensitive to inducing field, and that comparison is probably reasonably accurate. Multicomponent remanence tends to produce an apparently harder demagnetization curve (i.e., greater MDF) than a comparable single component (this is a result of the geometry of vector demagnetization curves and has nothing to do with intrinsic magnetic properties). This effect is generally small and is not found in all samples in any case. Often a significant portion of the NRM is left at $1000 \mathrm{Oe}$ (the limit of our machine). $\mathrm{MDF}_{\mathrm{A}}$ would then only reflect the portion of the grains that can be affected by 1000 -Oe fields and would be somewhat lower than $\mathrm{MDF}_{\mathrm{N}}$. This difference is easily corrected for, however, and is not sufficient to eliminate the disparity in MDF in many, if not most, samples. The comparison of results with those of Levi and Merrill (1976) may not be valid. They worked with pure magnetite, and only one of their samples was in the single-domain size range found for most (though not all) of the Leg 82 rocks (note that this sample had $\mathrm{J}_{\mathrm{A}} / \mathrm{J}_{\mathrm{N}}=0.24$ and $\mathrm{MDF}_{\mathrm{A}}$ / $\left.\mathrm{MDF}_{\mathrm{N}}=1.2\right)$. Although further work is necessary, the consistency of their results suggests that more directly comparable samples would show similar behavior.

All factors taken into consideration, many, if not most, of the samples still seem to show distinctly different behaviors for NRM and ARM (and presumably TRM). It is well known that oxidation tends to decrease remanence and increase stability relative to their original values (e.g., Johnson, 1979). We tentatively conclude from these data that oxidation also causes these same changes relative to intrinsic (oxidized) magnetic parameters. This behavior suggests that we are not simply seeing a reduction in TRM but, in fact, its replacement by a chemical rema- 
nence with entirely different character, as in fact suggested by Hall (1977) on somewhat different grounds. Unfortunately, these data tell us nothing about possible effects on the direction of remanence.

\section{SUMMARY}

In general, these basalts are very similar to other such rocks recovered by DSDP. The most notable distinction was that they were unusually stable magnetically. Although they span a broad area of seafloor, they show no substantial trends either with latitude or age; however, there appears to be a small increase in $\mathrm{J}_{\mathrm{s}}$ with decreasing latitude. The remanence appears to be dominated by a chemical remanent magnetization produced by low temperature alteration of the original TRM-bearing titanomagnetites. This remanence seems to be distinctly different from what would exist if the samples could be given a TRM in their oxidized state, having a lesser remanence and a greater stability. Nevertheless, the validity of the ARM-TRM analogy remains to be confirmed. There is also some evidence that the Ti content of the titanomagnetites may be more variable than often supposed. This too will require further study.

\section{ACKNOWLEDGMENTS}

We would like to thank Wendy Tormanen and Yvonne Meeks for their assistance with some of the measurements. Valuable assistance was also rendered on many occasions by Jim Marvin. We would also like to thank our reviewers, S. Beske-Diehl, B. Moskowitz, and R. Merrill, for many helpful comments and criticisms. This work was performed under NSF Grants OCE-8018692 and OCE-8214652.

\section{REFERENCES}

Day, R., Fuller, M.D., and Schmidt, V. A., 1977. Hysteresis properties of titanomagnetites: grain size and composition dependence. Phys. Earth Planet. Inter., 13:260.

Halgedahl, S., and Fuller, M. D., 1983. The dependence of magnetic domain structure upon magnetization state with emphasis upon nucleation as a mechanism for pseudo-single-domain behavior. $J$. Geophys. Res., 88:6505-6522.

Hall, J. M., 1977. Does TRM occur in oceanic layer 2 basalts? J. Geomagn. Geoelectr., 29:411-420.

Johnson, H.P., 1979. Magnetization of the oceanic crust. Rev. Geophys. Space Phys., 17:215-226.

Levi, S., and Merrill, R. T., 1976. A comparison of ARM and TRM in magnetite. Earth Planet. Sci. Lett., 32:171-184.

Moskowitz, B. M., 1981. Methods for estimating Curie temperatures of titanomagnetites from experimental $\mathrm{J}_{\mathrm{s}}-\mathrm{T}$ data. Earth Planet. Sci. Lett., 53:84-88.

Moskowitz, B. M., and Banerjee, S. K., 1981. Magnetic properties of synthetic titanomaghemites and some oceanic basalts. J. Geophys. Res., 86:11869-11882.

O'Reilly, W., 1983. The identification of titanomaghemites: model mechanisms for the maghemitization and inversion processes and their magnetic consequences. Phys. Earth Planet. Sci., 31:65-76.

Readman, P. W., and O"Reilly, W. O., 1972. Magnetic properties of oxidized (cation deficient) titanomagnetites $(\mathrm{Fe}, \mathrm{Ti}, \square)_{3} \mathrm{O}_{4} . \quad J$. Geomagn. Geoelectr., 24:69-90.

Steiner, M., 1982. An investigation of ulvospinel composition and cation migration during maghemitization in Deep Sea Drilling Project Leg 61 titanomagnetites. J. Geophys. Res., 87:5361-5374.

Syono, Y., 1965. Magnetocrystalline anisotropy and magnetostriction of $\mathrm{Fe}_{3} \mathrm{O}_{4}-\mathrm{Fe}_{2} \mathrm{TiO}_{4}$ series, with special application to rock magnetization. Jpn. J. Geophys., 4:71-142.

Date of Initial Receipt: 31 May 1983

Date of Acceptance: 16 November 1983 
APPENDIX A

Remanent Properties

\begin{tabular}{|c|c|c|c|c|c|c|c|c|c|c|}
\hline $\begin{array}{l}\text { Core-Section } \\
\text { (interval in cm) }\end{array}$ & $\left(\mathrm{emu}^{\mathrm{J}} \cdot \mathrm{cm}^{\mathrm{J}}-3\right)$ & $\begin{array}{c}1 \\
\left({ }^{\circ}\right)\end{array}$ & $\begin{array}{l}\mathrm{MDF}_{\mathrm{N}} \\
(\mathrm{Oe})^{\mathrm{a}}\end{array}$ & $\underset{\left(\mathrm{emu} / \mathrm{cm}^{3}\right)}{\mathrm{J}_{\mathrm{A}}}$ & $\begin{array}{l}\mathrm{MDF}_{\mathrm{A}} \\
(\mathrm{Oe})\end{array}$ & $\frac{\mathrm{J}_{\mathrm{A}}}{\mathrm{J}_{\mathrm{N}}}$ & $\frac{\mathrm{MDF}_{\mathrm{A}}}{\mathrm{MDF}_{\mathrm{N}}}$ & $\left(\mathrm{emu} \cdot \mathrm{cm}^{\mathrm{x}_{0}}-\mathrm{Oe}^{-1}\right)$ & Q & Description \\
\hline \multicolumn{11}{|l|}{ Hole 556} \\
\hline $5-1,78-80$ & $4.01 \times 10^{-3}$ & -31 & 562 & $2.04 \times 10^{-3}$ & 371 & 0.51 & 0.66 & $8.29 \times 10^{-5}$ & 96.7 & Pillow interior \\
\hline $5-1,111-113$ & $1.27 \times 10^{-3}$ & $-35^{b}$ & 675 & $1.96 \times 10^{-3}$ & 323 & 1.54 & 0.48 & $9.98 \times 10^{-5}$ & 25.5 & Pillow margin \\
\hline $7-1,47-49$ & $2.02 \times 10^{-3}$ & -25 & 274 & $2.42 \times 10^{-3}$ & 200 & 1.20 & 0.73 & $1.41 \times 10^{-4}$ & 28.7 & Flow margin \\
\hline $7-3,18-21$ & $6.36 \times 10^{-4}$ & -30 & 315 & $2.30 \times 10^{-3}$ & 200 & 3.59 & 0.63 & $1.11 \times 10^{-4}$ & 11.5 & Flow interior \\
\hline $8-2,6-9$ & $3.05 \times 10^{-3}$ & -38 & $\begin{array}{l}481 \\
540\end{array}$ & $2.02 \times 10^{-3}$ & 374 & 0.66 & 0.78 & $1.50 \times 10^{-4}$ & 40.7 & Pillow interior \\
\hline $9-1,143-146$ & $7.24 \times 10^{-4}$ & $-6^{b}$ & 540 & $1.26 \times 10^{-3}$ & 297 & 1.73 & 0.55 & $1.04 \times 10^{-4}$ & 13.9 & Flow interior \\
\hline Average & $1.95 \times 10^{-3}$ & -28 & 475 & $1.96 \times 10^{-3}$ & 294 & 1.54 & 0.64 & $1.15 \times 10^{-4}$ & 36.2 & \\
\hline \multicolumn{11}{|l|}{ Hole 557} \\
\hline $1-1,46-49$ & $4.38 \times 10^{-3}$ & -55 & 99 & $7.34 \times 10^{-3}$ & 34 & 1.68 & 0.34 & $2.76 \times 10^{-3}$ & 3.2 & Basalt \\
\hline $1-1,120-123$ & $1.08 \times 10^{-2}$ & -46 & 113 & $5.96 \times 10^{-3}$ & 74 & 0.55 & 0.65 & $1.05 \times 10^{-3}$ & 20.6 & Basalt \\
\hline Average & $7.59 \times 10^{-3}$ & -51 & 106 & $6.52 \times 10^{-3}$ & 54 & 1.12 & 0.50 & $1.19 \times 10^{-3}$ & 11.9 & \\
\hline \multicolumn{11}{|l|}{ Hole 558} \\
\hline $27-3,51-54$ & $3.70 \times 10^{-4}$ & $-51^{b}$ & 690 & $1.51 \times 10^{-3}$ & 282 & 4.08 & 0.41 & $8.98 \times 10^{-5}$ & 8.2 & \\
\hline $27-3,123-126$ & $1.81 \times 10^{-3}$ & -45 & 405 & $3.00 \times 10^{-3}$ & $\begin{array}{l}165 \\
165\end{array}$ & 1.66 & 0.41 & $1.24 \times 10^{-4}$ & 29.2 & Pillow interior \\
\hline $28-3,9-12$ & $4.19 \times 10^{-4}$ & $\begin{array}{l}-43 \\
-20^{b}\end{array}$ & 739 & $2.18 \times 10^{-3}$ & 372 & $\begin{array}{l}1.00 \\
5.20\end{array}$ & $\begin{array}{l}0.41 \\
0.50\end{array}$ & $1.13 \times 10^{-4}$ & $\begin{array}{r}79.2 \\
7.4\end{array}$ & Pillow margin \\
\hline $28-3,43-47$ & $2.05 \times 10^{-3}$ & -23 & 248 & $4.44 \times 10^{-3}$ & 181 & 2.17 & 0.73 & $2.25 \times 10^{-4}$ & 18.2 & Pillow interior \\
\hline $29-2,138-141$ & $3.63 \times 10^{-3}$ & $+34^{\mathrm{b}}$ & 541 & $2.33 \times 10^{-3}$ & $\begin{array}{l}7101 \\
369\end{array}$ & 0.64 & 0.68 & $1.73 \times 10^{-4}$ & $\begin{array}{l}42.0 \\
42.0\end{array}$ & Pillow interior \\
\hline $29-2,100-103$ & $1.11 \times 10^{-3}$ & $\begin{array}{l}+34 \\
+29\end{array}$ & $\begin{array}{l}341 \% \\
61 \%\end{array}$ & $4.23 \times 10^{-4}$ & $\begin{array}{l}369 \\
769\end{array}$ & 0.38 & 0.08 & $7.08 \times 10^{-5}$ & 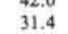 & Pillow margin \\
\hline $32-5,30-33$ & $2.85 \times 10^{-3}$ & -39 & 475 & $2.37 \times 10^{-3}$ & $\begin{array}{l}109 \\
277\end{array}$ & 0.83 & 0.58 & $1.08 \times 10^{-4}$ & $\begin{array}{l}52.4 \\
52.8\end{array}$ & Flow interior \\
\hline $32-5,106-109$ & $1.32 \times 10^{-3}$ & -42 & 652 & $2.04 \times 10^{-3}$ & 359 & $\begin{array}{l}.83 \\
1.55\end{array}$ & 0.55 & $8.32 \times 10^{-5}$ & 31.7 & Flow margin \\
\hline $35-2,7174$ & $1.82 \times 10^{-4}$ & -72 & $80 \%$ & $3.49 \times 10^{-4}$ & 244 & 1.92 & 0.30 & $6.89 \times 10^{-5}$ & 5.3 & Pillow margin \\
\hline $35-2,98-101$ & $2.18 \times 10^{-3}$ & -54 & 681 & $1.53 \times 10^{-3}$ & 362 & 0.70 & 0.53 & $6.08 \times 10^{-5}$ & 71.7 & Pillow interior \\
\hline $36-2,130-133$ & $4.55 \times 10^{-4}$ & -44 & 667 & $1.66 \times 10^{-3}$ & $\begin{array}{l}302 \\
367\end{array}$ & 3.65 & 0.55 & $8.22 \times 10^{-5}$ & 11.1 & Flow margin \\
\hline $36-3,18-21$ & $7.74 \times 10^{-3}$ & $-51^{b}$ & $\begin{array}{l}001 \\
685\end{array}$ & $1.52 \times 10^{-3}$ & $\begin{array}{l}3671 \\
321\end{array}$ & 0.20 & 0.47 & $9.00 \times 10^{-5}$ & 172.0 & Flow interior \\
\hline $38-1,56-59$ & $2.34 \times 10^{-3}$ & -33 & 444 & $3.48 \times 10^{-3}$ & 226 & $\begin{array}{l}0.20 \\
1.49\end{array}$ & 0.51 & $1.25 \times 10^{-4}$ & 37.4 & Pillow margin \\
\hline $38-2,42-45$ & $3.65 \times 10^{-3}$ & $\begin{array}{r}30 \\
+32\end{array}$ & 258 & $2.71 \times 10^{-3}$ & 182 & 0.74 & 0.71 & $1.70 \times 10^{-4}$ & 42.9 & Pillow interior \\
\hline $39-4,4-7$ & $3.31 \times 10^{-3}$ & -26 & 421 & $2.43 \times 10^{-3}$ & 388 & 0.73 & 0.92 & $1.04 \times 10^{-4}$ & 63.7 & Possible flow \\
\hline $39-4,55-57$ & $1.82 \times 10^{-3}$ & -26 & 485 & $1.40 \times 10^{-3}$ & 285 & 0.77 & 0.59 & $8.40 \times 10^{-5}$ & 43.3 & Possible flow \\
\hline Average & $2.20 \times 10^{-3}$ & $-40^{\mathrm{C}}$ & 528 & $2.09 \times 10^{-3}$ & 322 & 1.67 & 0.58 & $1.11 \times 10^{-4}$ & 32.1 & \\
\hline \multicolumn{11}{|l|}{ Hole 559} \\
\hline $4-1,115-118$ & $6.40 \times 10^{-4}$ & & & $1.54 \times 10^{-3}$ & 315 & & 0.48 & $1.20 \times 10^{-4}$ & & Pillow interior \\
\hline $4-1,133-136$ & $6.87 \times 10^{-4}$ & -37 & $\begin{array}{l}031 \\
460\end{array}$ & $1.82 \times 10^{-3}$ & 292 & 2.64 & $\begin{array}{l}0.48 \\
0.63\end{array}$ & $1.34 \times 10^{-4}$ & 10.3 & $\begin{array}{l}\text { Pillow interior } \\
\text { Pillow margin }\end{array}$ \\
\hline $6-2,20-23$ & $5.34 \times 10^{-4}$ & $-30^{\mathrm{b}}$ & 804 & $1.27 \times 10^{-3}$ & 323 & 2.40 & 0.40 & $1.10 \times 10^{-4}$ & 9.7 & Pillow interior \\
\hline $6-2,50-53$ & $1.77 \times 10^{-4}$ & $+27^{\mathrm{b}}$ & $55 \%$ & $2.73 \times 10^{-3}$ & 267 & 15.4 & & $1.08 \times 10^{-4}$ & 3.3 & Pillow margin \\
\hline Average & $5.10 \times 10^{-4}$ & $33^{\mathrm{c}}$ & $638^{d}$ & $1.84 \times 10^{-3}$ & 299 & 5.64 & 0.50 & $1.18 \times 10^{-4}$ & 8.5 & \\
\hline \multicolumn{11}{|l|}{ Hole 561} \\
\hline $2-2,15-18$ & $2.35 \times 10^{-3}$ & -62 & 303 & $4.09 \times 10^{-3}$ & 283 & 1.74 & 0.93 & $3.39 \times 10^{-4}$ & 13.9 & Pillow margin \\
\hline $2-2,45-48$ & $3.31 \times 10^{-3}$ & -59 & 345 & $3.61 \times 10^{-3}$ & 299 & 1.09 & 0.87 & $3.50 \times 10^{-4}$ & 18.9 & Pillow interior \\
\hline 3-1. $67-70$ & $3.07 \times 10^{-3}$ & $-53 \mathrm{~b}$ & 346 & $3.86 \times 10^{-3}$ & 312 & 1.26 & 0.90 & $3.19 \times 10^{-4}$ & 19.2 & Massive flow \\
\hline $3-2,42-45$ & $1.37 \times 10^{-3}$ & $-44^{b}$ & 341 & $3.53 \times 10^{-3}$ & 257 & 2.58 & 0.75 & $2.7 \times 10^{-4}$ & 10.1 & Massive flow \\
\hline Average & $2.53 \times 10^{-3}$ & -55 & 334 & $3.77 \times 10^{-3}$ & 288 & 1.67 & 0.86 & $3.20 \times 10^{-4}$ & 15.5 & \\
\hline \multicolumn{11}{|l|}{ Hole 562} \\
\hline $1-2,27-30$ & $8.81 \times 10^{-4}$ & -33 & 513 & $7.81 \times 10^{-3}$ & 100 & 8.90 & 0.19 & $8.49 \times 10^{-4}$ & 2.1 & Pillow margin \\
\hline $1-2,61-64$ & $2.43 \times 10^{-3}$ & -50 & 363 & $3.78 \times 10^{-3}$ & 210 & 1.56 & 0.58 & $2.00 \times 10^{-4}$ & 24.3 & Pillow interior \\
\hline $4-2,38-41$ & $1.67 \times 10^{-3}$ & -36 & 353 & $4.44 \times 10^{-3}$ & 131 & 2.66 & 0.37 & $2.94 \times 10^{-4}$ & 11.4 & Massive flow \\
\hline $4-3,72-75$ & $1.85 \times 10^{-3}$ & -35 & 132 & $3.83 \times 10^{-3}$ & 86 & 2.07 & 0.65 & $3.47 \times 10^{-4}$ & 10.7 & Flow margin \\
\hline $4-3,129-132$ & $6.90 \times 10^{-4}$ & -30 & 478 & $3.20 \times 10$ & 309 & 4.64 & 0.65 & $1.77 \times 10^{-4}$ & 7.8 & Pillow margin \\
\hline 4.4. 30-33 & $2.19 \times 10^{-3}$ & -31 & 526 & $2.71 \times 10^{-}$ & 357 & 1.24 & 0.68 & $8.39 \times 10^{-5}$ & 52.0 & Pillow interior \\
\hline $5.2 .78-81$ & $2.14 \times 10^{-3}$ & -33 & 414 & $5.03 \times 10^{-3}$ & 154 & 2.35 & 0.37 & $4.51 \times 10^{-4}$ & 9.5 & Flow margin \\
\hline $5.2,104-107$ & $1.13 \times 10^{-3}$ & -26 & 282 & $3.61 \times 10^{-3}$ & 232 & 3.19 & 0.82 & $3.28 \times 10^{-4}$ & 6.9 & Flow interior \\
\hline $6-3,19-22$ & $3.13 \times 10^{-3}$ & -31 & 736 & $3.20 \times 10^{-3}$ & 685 & 1.02 & 0.93 & $9.27 \times 10^{-5}$ & 67.5 & Pillow margin \\
\hline $6-3,61-64$ & $2.39 \times 10^{-3}$ & -29 & 505 & $2.85 \times 10^{-3}$ & 346 & 1.19 & 0.69 & $9.33 \times 10^{-5}$ & 51.2 & Pillow interior \\
\hline Average & $1.85 \times 10^{-3}$ & -33 & 430 & $4.05 \times 10^{-3}$ & 261 & 2.88 & 0.59 & $2.92 \times 10^{-4}$ & 24.3 & \\
\hline \multicolumn{11}{|l|}{ Hole 563} \\
\hline $24-1,3-6$ & $1.96 \times 10^{-3}$ & & 315 & $4.94 \times 10^{-3}$ & 207 & 2.52 & 0.66 & $4.27 \times 10^{-4}$ & 9.2 & Pillow interior \\
\hline $24-1,33-36$ & $4.96 \times 10^{-3}$ & $\begin{array}{l}+42 \\
+47\end{array}$ & 271 & $4.86 \times 10^{-3}$ & 327 & 0.98 & $\begin{array}{l}1.00 \\
1.21\end{array}$ & $3.43 \times 10^{-4}$ & 28.9 & Pillow margin \\
\hline Average & $3.46 \times 10^{-3}$ & +45 & 293 & $4.90 \times 10^{-3}$ & 267 & 1.75 & 0.94 & $3.85 \times 10^{-4}$ & 19.1 & \\
\hline \multicolumn{11}{|l|}{ Hole 564} \\
\hline $1-3,4$. & $1.94 \times 10^{-3}$ & +10 & 549 & $1.29 \times 10$ & 31 & 0. & 0 & $1.33 \times 10^{-4}$ & 29.2 & \\
\hline $46-47$ & $3.77 \times 10^{-3}$ & -5 & 379 & $4.34 \times$ & 296 & 1.15 & 0.7 & $1.82 \times 10^{-4}$ & 41.4 & Pillow margin \\
\hline $5-3,93-96$ & $1.93 \times 10^{-3}$ & +26 & 457 & $6.01 \times 1$ & 182 & 3.11 & 0. & $1.95 \times$ & 19.8 & Flow interior \\
\hline $5-3,44-47$ & $1.52 \times 10^{-3}$ & +14 & 444 & $3.37 \times 1$ & 351 & 2.22 & 0.7 & $1.82 \times 1$ & 16.7 & Flow margin \\
\hline $6-2,104-107$ & $5.15 \times 10^{-3}$ & +9 & 129 & $8.11 \times 10$ & 195 & 1.57 & 1.51 & $1.04 \times 10$ & 10.6 & Pillow margin \\
\hline $6-2,50-53$ & $2.30 \times 10^{-3}$ & +28 & 554 & $4.72 \times 10$ & 199 & 2.05 & 0.36 & $1.88 \times 10$ & 24.5 & Pillow interior \\
\hline $8-2,75-78$ & $3.88 \times 10^{-}$ & -20 & 240 & $4.94 \times 10^{-}$ & 154 & 1.27 & 0.64 & $2.88 \times 1$ & 26.9 & Flow interior \\
\hline $9-2,71-74$ & $1.84 \times 10^{-3}$ & +15 & 326 & $5.94 \times 10^{-3}$ & 326 & 3.23 & 1.0 & $1.63 \times 10^{-4}$ & 22.6 & Flow margin \\
\hline Average & $2.78 \times 10^{-3}$ & $+17^{\mathrm{e}}$ & 385 & $4.84 \times 10^{-3}$ & 253 & 1.91 & 0.76 & $2.94 \times 10^{-4}$ & 24.0 & \\
\hline
\end{tabular}

Note: $J_{N}$ is the natural remanent magnetization; $I$ is the inclination; MDF $N$ is median demagnetizing field for $N R M ; J_{A}$ is the anysteretic remanent magnetiza tion (ARM) value; $M_{\text {DFF }}$ is the median demagnetizing field for ARM: $x_{0}$ is weak field susceptibility; and $Q$ is the Koenigsberger ratio $\left(J_{N} / 0.5 X_{O}\right)$. a $\%$ in this column indicates the remanence remaining at 1000 Oe. b $\%$ in this column indicates the $\mathrm{r}$

c. Excludes values with different polarity than the majority of samples.

d Excludes values with different polarity tha
Excludes samples wih MDF $>1000$ Oe. 
APPENDIX B

Intrinsic Properties

\begin{tabular}{|c|c|c|c|c|c|c|c|c|c|c|}
\hline \multirow{2}{*}{$\begin{array}{l}\text { Core-Section } \\
\text { (interval in cm) }\end{array}$} & \multirow{2}{*}{$\left.\underset{(e m u \cdot g}{J_{5}}-1\right)$} & \multirow{2}{*}{$\underset{(e m u \cdot g}{\stackrel{J}{r}}-1)$} & \multirow{2}{*}{$\begin{array}{l}\mathrm{H}_{\mathrm{c}} \\
(\mathrm{Oc})\end{array}$} & \multirow{2}{*}{$\begin{array}{l}\mathrm{H}_{\mathrm{cr}} \\
(\mathrm{Oe})\end{array}$} & \multirow{2}{*}{$\frac{\mathrm{J}_{\mathrm{T}}}{\mathrm{J}_{\mathrm{S}}}$} & \multirow{2}{*}{$\frac{\mathrm{H}_{\mathrm{cr}}}{\mathrm{H}_{\mathrm{c}}}$} & $\left(\mathrm{emu} \cdot \mathrm{g}^{\mathrm{xp}_{1}} \cdot \mathrm{Oe^{-1 }}\right.$ & $T_{c}$ & $\left.{ }^{\circ} \mathrm{C}\right)$ & $\mathrm{J}_{\mathrm{f}}$ \\
\hline & & & & & & & & Heating & Cooling & $\mathrm{J}_{\mathrm{A}}$ \\
\hline Hole 556 & & & & & & & & & & \\
\hline $5-1,78-80$ & $1.27 \times 10^{-1}$ & $8.25 \times 10^{-2}$ & 372 & 463 & 0.65 & 1.2 & 1.59 & 270 & 545 & 10.6 \\
\hline $5-1,111-113$ & $8.95 \times 10^{-2}$ & $6.04 \times 10^{-2}$ & 419 & 581 & 0.67 & 1.4 & 1.54 & 315 & 535 & 10.0 \\
\hline $7-1,47-49$ & $1.26 \times 10^{-1}$ & $5.79 \times 10^{-2}$ & 198 & 269 & 0.46 & 1.4 & 1.13 & 355 & 590 & 8.8 \\
\hline $7-3,18-21$ & $1.49 \times 10^{-1}$ & $8.10 \times 10^{-2}$ & 198 & 238 & 0.54 & 1.2 & 1.36 & 310 & 560 & 6.1 \\
\hline $8-2,6-9$ & $1.11 \times 10^{-1}$ & $5.67 \times 10^{-2}$ & 269 & 363 & 0.51 & 1.35 & 1.08 & 380 & 610 & 7.3 \\
\hline $8 \cdot 2,80-83$ & $2.77 \times 10^{-2}$ & $1.26 \times 10^{-2}$ & 175 & 388 & 0.45 & 2.2 & 1.42 & 495 & 560 & 4.1 \\
\hline $9-1,143-146$ & $1.15 \times 10^{-1}$ & $5.59 \times 10^{-2}$ & 259 & 363 & 0.49 & 1.4 & 1.32 & 365 & 575 & 8.4 \\
\hline $9-1,127-130$ & $7.86 \times 10^{-2}$ & $4.35 \times 10^{-2}$ & 364 & 561 & 0.55 & 1.5 & 1.22 & 365 & 590 & 11.7 \\
\hline Average & $1.03 \times 10^{-1}$ & $5.63 \times 10^{-2}$ & 282 & 403 & 0.54 & 1.5 & 1.33 & 357 & 571 & 8.1 \\
\hline Hole 557 & & & & & & & & & & \\
\hline $1-1,46-49$ & 1.47 & $1.89 \times 10^{-1}$ & 39 & 91 & 0.13 & 2.3 & 1.45 & 195 & & 1.0 \\
\hline $1-1,120-123$ & 1.48 & $2.80 \times 10^{-1}$ & 88 & 139 & 0.19 & 1.6 & 3.14 & 350 & 445 & 0.3 \\
\hline Average & 1.48 & $2.35 \times 10^{-1}$ & 64 & 115 & 0.16 & 2.0 & 2.30 & 273 & 445 & 0.7 \\
\hline Hole 558 & & & & & & & & & & \\
\hline $27-3,51-54$ & $1.22 \times 10^{-1}$ & $5.01 \times 10^{-2}$ & 189 & 297 & 0.41 & 1.6 & 1.16 & 340 & 570 & 6.6 \\
\hline $27-3,123-126$ & $1.83 \times 10^{-1}$ & $9.17 \times 10^{-2}$ & 173 & 247 & 0.50 & 1.4 & 1.55 & 265 & 445 & 5.0 \\
\hline $28-3,9-12$ & $7.32 \times 10^{-2}$ & $3.66 \times 10^{-2}$ & 298 & 456 & 0.50 & 1.5 & 1.29 & 350 & 565 & 8.0 \\
\hline $28-3,43-47$ & $1.16 \times 10^{-1}$ & $6.93 \times 10^{-2}$ & 317 & 398 & 0.60 & 1.3 & 1,45 & 295 & 545 & 5.6 \\
\hline $29-2,138-141$ & $1.11 \times 10^{-1}$ & $6.46 \times 10^{-2}$ & 278 & 311 & 0.58 & 1.1 & 1.57 & 320 & 540 & 5.1 \\
\hline $29-2,100-103$ & $4.05 \times 10^{-2}$ & $2.02 \times 10^{-2}$ & 431 & & 0.50 & & 1.48 & 375 & 570 & 2.4 \\
\hline $32-5,30-33$ & $1.44 \times 10^{-1}$ & $6.66 \times 10^{-2}$ & 247 & 399 & 0.46 & 1.4 & 1.38 & 305 & 560 & 7.6 \\
\hline $32-5,106-109$ & $1.03 \times 10^{-1}$ & $5.66 \times 10^{-2}$ & 306 & 427 & 0.55 & 1.4 & 1.36 & 295 & 560 & 8.2 \\
\hline $35-2,71-74$ & $2.66 \times 10^{-2}$ & $1.51 \times 10^{-2}$ & 428 & & 0.57 & & 1.33 & 385 & 580 & 4.8 \\
\hline $35-2,98-101$ & $1.14 \times 10^{-1}$ & $7.03 \times 10^{-2}$ & 472 & 636 & 0.62 & 1.4 & 1.46 & 310 & 570 & 6.8 \\
\hline $36-2,130-133$ & $5.33 \times 10^{-2}$ & $3.24 \times 10^{-2}$ & 353 & 541 & 0.61 & 1.5 & 1.04 & 360 & 550 & 9.9 \\
\hline $36-3,18-21$ & $1.43 \times 10^{-1}$ & $8.76 \times 10^{-2}$ & 411 & 542 & 0.61 & 1.3 & 1.46 & 320 & 580 & 6.0 \\
\hline $38-1,56-59$ & $1.59 \times 10^{-1}$ & $7.41 \times 10^{-2}$ & 172 & 238 & 0.47 & 1.4 & 1.41 & 315 & 555 & 5.1 \\
\hline $38-2,42-45$ & $2.15 \times 10^{-1}$ & $9.95 \times 10^{-2}$ & 202 & 275 & 0.46 & 1.4 & 1.41 & 295 & 530 & 4.7 \\
\hline $39-4,4-7$ & $9.64 \times 10^{-2}$ & $4.92 \times 10^{-2}$ & 244 & 339 & 0.51 & 1.4 & 1.10 & 350 & 555 & 8.8 \\
\hline $39.4,55-57$ & $8.35 \times 10^{-2}$ & $4.76 \times 10^{-2}$ & 284 & 398 & 0.57 & 1.4 & 1.20 & 320 & 580 & 11.9 \\
\hline Average & $1.11 \times 10^{-1}$ & $5.82 \times 10^{-2}$ & 300 & 389 & 0.53 & 1.4 & 1.35 & 325 & 553 & 6.3 \\
\hline Hole 559 & & & & & & & & & & \\
\hline $4-1,115-118$ & $1.15 \times 10^{-1}$ & $5.97 \times 10^{-2}$ & 283 & 413 & 0.52 & 1.5 & 1.42 & 310 & 580 & 9.5 \\
\hline $4-1,133-136$ & $8.44 \times 10^{-2}$ & $4.62 \times 10^{-2}$ & 309 & 463 & 0.55 & 1.5 & 0.93 & 315 & 560 & 10.8 \\
\hline $6-2,20-23$ & $7.82 \times 10^{-2}$ & $4.86 \times 10^{-2}$ & 391 & 594 & 0.62 & 1.5 & 1.34 & 365 & 590 & 10.0 \\
\hline $6-2,50-53$ & $5.92 \times 10^{-2}$ & $3.33 \times 10^{-2}$ & 281 & 466 & 0.56 & 1.7 & 1.16 & 395 & 580 & 11.2 \\
\hline Average & $8.42 \times 10^{-2}$ & $4.70 \times 10^{-2}$ & 316 & 484 & 0.56 & 1.6 & 1.21 & 346 & 578 & 10.4 \\
\hline Hole 561 & & & & & & & & & & \\
\hline $2-2,15-18$ & $2.80 \times 10^{-1}$ & $1.33 \times 10^{-1}$ & 230 & 278 & 0.48 & 1.2 & 1.65 & 375 & 545 & 2.7 \\
\hline $2-2,45-48$ & $3.16 \times 10^{-1}$ & $1.37 \times 10^{-1}$ & 272 & 384 & 0.43 & 1.4 & 1.62 & 335 & 570 & 4.2 \\
\hline $3-1,67-70$ & $2.93 \times 10^{-1}$ & $1.40 \times 10^{-1}$ & 248 & 330 & 0.48 & 1.3 & 1.49 & 340 & (a) & \\
\hline $3-2,42-45$ & $3.06 \times 10^{-1}$ & $1.37 \times 10^{-1}$ & 242 & 338 & 0.45 & 1.4 & 1.70 & 305 & 575 & 4.7 \\
\hline Average & $2.99 \times 10^{-1}$ & $1.37 \times 10^{-1}$ & 248 & 333 & 0.46 & 1.3 & 1.62 & 339 & 563 & 3.9 \\
\hline Hole 562 & & & & & & & & & & \\
\hline $1-2,27-30$ & $5.80 \times 10^{-1}$ & $1.70 \times 10^{-1}$ & 106 & 194 & 0.29 & 1.8 & 2.07 & 205 & (a) & 1.1 \\
\hline $1-2,61-64$ & $2.55 \times 10^{-1}$ & $1.20 \times 10^{-1}$ & 211 & 278 & 0.47 & 1.3 & 1.83 & 290 & 565 & 5.8 \\
\hline $4-2,38-41$ & $2.54 \times 10^{-1}$ & $1.04 \times 10^{-1}$ & 172 & 230 & 0.41 & 1.3 & 1.49 & 305 & 520 & \\
\hline $4-3,72-75$ & $3.83 \times 10^{-1}$ & $1.30 \times 10^{-1}$ & 145 & 217 & 0.34 & 1.5 & 1.96 & 270 & 550 & 4.2 \\
\hline $4-3,129-132$ & $6.03 \times 10^{-2}$ & $2.49 \times 10^{-2}$ & 188 & 413 & 0.41 & 2.2 & 1.43 & 525 & 570 & 4.5 \\
\hline $4-4,30-33$ & $1.31 \times 10^{-1}$ & $8.62 \times 10^{-2}$ & 304 & 467 & 0.66 & 1.3 & 1.50 & 260 & 545 & 8.6 \\
\hline $5-2,78-81$ & $5.03 \times 10^{-1}$ & $1.16 \times 10^{-1}$ & 89 & 169 & 0.23 & 1.9 & 1.93 & 260 & & \\
\hline $5-2,104-107$ & $2.99 \times 10^{-1}$ & $8.80 \times 10^{-2}$ & 139 & 217 & 0.29 & 1.6 & 1.47 & 370 & (a) & 1.4 \\
\hline $6-3,19-22$ & $1.32 \times 10^{-1}$ & $8.90 \times 10^{-2}$ & 517 & 728 & 0.67 & 1.4 & 1.71 & 315 & 550 & 3.9 \\
\hline $6-3,61-64$ & $1.15 \times 10^{-1}$ & $7.53 \times 10^{-2}$ & 388 & 513 & 0.66 & 1.3 & 1.49 & 285 & 530 & 6.3 \\
\hline Average & $2.71 \times 10^{-1}$ & $1.00 \times 10^{-1}$ & 226 & 343 & 0.44 & 1.6 & 1.69 & 309 & 547 & 4.5 \\
\hline Hole 563 & & & & & & & & & & \\
\hline $24-1,3-6$ & $3.24 \times 10^{-1}$ & $1.32 \times 10^{-1}$ & 173 & 238 & 0.41 & 1.4 & 1.35 & 415 & 575 & 3.4 \\
\hline $24-1,33-36$ & $2.66 \times 10^{-1}$ & $1.05 \times 10^{-1}$ & 236 & 331 & 0.40 & 1.4 & 1.38 & 415 & & 3.3 \\
\hline Average & $2.95 \times 10^{-1}$ & $1.19 \times 10^{-1}$ & 205 & 285 & 0.41 & 1.4 & 1.37 & 415 & 575 & 3.4 \\
\hline Hole 564 & & & & & & & & & & \\
\hline $1-3,4-7$ & $1.38 \times 10^{-1}$ & $7.41 \times 10^{-2}$ & 313 & 472 & 0.54 & 1.5 & 1.43 & 375 & 580 & 9.2 \\
\hline $1-1,46-49$ & $2.80 \times 10^{-1}$ & $1.42 \times 10^{-1}$ & 255 & 334 & 0.51 & 1.3 & 1.66 & 340 & 555 & 5.3 \\
\hline $5-3,93-96$ & $2.68 \times 10^{-1}$ & $1.35 \times 10^{-1}$ & 188 & 233 & 0.51 & 1.2 & 1.68 & 305 & 560 & 6.2 \\
\hline $5-3,44-47$ & $1.78 \times 10^{-1}$ & $7.52 \times 10^{-2}$ & 214 & 336 & 0.42 & 1.6 & 1.39 & 380 & 575 & 5.3 \\
\hline $6-2,104-107$ & $4.79 \times 10^{-1}$ & $1.05 \times 10^{-1}$ & 88 & 159 & 0.22 & 1.8 & 1.38 & 505 & 575 & 1.3 \\
\hline $6-2,50-53$ & $2.61 \times 10^{-1}$ & $1.24 \times 10^{-1}$ & 191 & 259 & 0.48 & 1.4 & 1.75 & 295 & 550 & 5.4 \\
\hline $8-2,75-78$ & $4.76 \times 10^{-1}$ & $1.99 \times 10^{-1}$ & 145 & 191 & 0.42 & 1.3 & 2.21 & 285 & 560 & 3.6 \\
\hline $9-2,71-74$ & $3.11 \times 10^{-2}$ & $1.48 \times 10^{-2}$ & 227 & 373 & 0.48 & 1.6 & 0.54 & 350 & 560 & 14.7 \\
\hline $9-3,18-21$ & $1.92 \times 10^{-1}$ & $6.81 \times 10^{-2}$ & 231 & 473 & 0.36 & 2.1 & 1.72 & 575 & 555 & 1.2 \\
\hline Average & $2.56 \times 10^{-1}$ & $1.04 \times 10^{-1}$ & 206 & 314 & 0.44 & 1.5 & 1.53 & 357 & 563 & 5.8 \\
\hline
\end{tabular}

Note: $\mathrm{J}_{\mathrm{s}}$ is saturation magnetization; $\mathrm{I}_{\mathrm{r}}$ is saturation remanence; $\mathrm{H}_{\mathrm{C}}$ is coercivity; $\mathrm{H}_{\mathrm{Cr}}$ is remanent coercivity; $\chi_{\mathrm{p}}$ is paramagnetic susceptibility; $\mathrm{T}_{\mathrm{c}}$ is Curie temperature; $\mathrm{J}_{\mathrm{f}}$ is $\mathrm{J}_{\mathrm{s}}$ after inversion; $\mathrm{J}_{\mathrm{i}}$ is $\mathrm{J}_{\mathrm{s}}$ before inversion. The heating value of $\mathrm{T}_{\mathrm{c}}$ is that before inversion; the cooling value

${ }^{a} \mathrm{~T}_{\mathrm{c}}$ too low to be measured accurately. 